Article

\title{
Dynamic Environmental Efficiency Assessment of Industrial Water Pollution
}

\author{
Ronggang Zhang ${ }^{1}$, Ching-Cheng Lu ${ }^{2} \oplus$, Jen-Hui Lee ${ }^{2}$, Ying Feng ${ }^{3} \oplus$ and Yung-Ho Chiu ${ }^{2, *}$ \\ 1 Business College, Northwest University of Political Science and Law, No. 558 West Chang An Road, \\ Chang An District, Xi'an 710122, China; 19970128@nwupl.edu.cn \\ 2 Department of Economics, Soochow University, 56, Kueiyang St., Sec. 1, Taipei 100, Taiwan; \\ 99451001@scu.edu.tw (C.-C.L.); 98451001@scu.edu.tw (J.-H.L.) \\ 3 Business College, Institute of Resource Conflict and Utilization Northwest University of Political Science and \\ Law, No. 558 West Chang An Road, Chang An District, Xi'an 710122, China; 20130099@nwupl.edu.cn \\ * Correspondence: echiu@scu.edu.tw; Tel.: +886-2-23111531 (ext. 5201); Fax: +886-2-27976015
}

Received: 11 May 2019; Accepted: 26 May 2019; Published: 30 May 2019

check for updates

\begin{abstract}
In the face of severe water pollution, all provinces and cities in China have actively invested in water environment management funds driven by the goals of national energy conservation and emissions reduction. However, due to differences in natural environment, economic and technological levels, industrial structure, and other aspects in provinces and cities, their water environment management effects are also different across time and space. Under economic development and environmental regulation policies, it can be seen that the change in industrial GDP is not completely consistent with that of industrial wastewater discharge. How to improve desirable outputs and reduce undesirable outputs under the limited investment in water pollution control are key issues when investigating the efficiency of industrial water pollution control. This study uses the Dynamic SBM (Slacks-Based Measure) model to assess wastewater resources for research samples covering the 30 regions of China. There are two output variables, two input variables, and one carry-over variable. The output variables are industrial wastewater treatment and industrial output, the two input variables are industrial water consumption and facility operation cost, and the carry-over variable is industrial waste. This study concludes with implications for theory research, as these variables may lead to a better understanding and merging with the input variables, output variables, and carry-over variable of recent studies. The empirical results show that from the efficiency rank changes of the 30 regions for 2011-2015, regions with higher industrial output do not appear to have improved versus other regions, such as for Shandong, Guangdong, Jiangsu, Qinghai, and Zhejiang. The 30 regions' efficiency scores show some volatility, with 13 regions' efficiency score volatility clustering close to 0, like Beijing, Chongqing, Shandong, Guangdong, and Sichuan. In contrast, for Anhui, Inner Mongolia, Zhejiang, and Xinjiang, their efficiency scores fell more than other regions in this period and thus should adjust their input/output variables to increase their efficiency scores. This study further presents that many lower-/middle-/high-industrial output regions do not achieve a balance between industrial output and industrial wastewater treatment. How to find a balance between these two factors for any region is a vitally important issue for industrial wastewater treatment policy makers. Under such a circumstance, an industrial output region may not actually be highly efficient at doing this.
\end{abstract}

Keywords: dynamic DEA (Data Envelopment Analysis); SBM; water pollution; environment; efficiency

\section{Introduction}

Industry plays an important role in promoting China's economic development. In 2015, the industrial GDP of 23,518 trillion yuan was 34 times as much as the 690.47 billion yuan in 
1990, accounting for 35.4\% of annual GDP. Between 1990 and 2015, the average industry contribution rate to GDP was $48.88 \%$, far greater than that of other industries. However, the relatively low level of industrial technology in China has resulted in high consumption of resources, greater pollution emissions, and very serious environmental pollution.

For a long time, water pollution control and its treatment have been one of the key tasks of China's environmental protection policy. From 2000 to 2015, China's investment into wastewater treatment increased by $60.41 \%$. At the same time, total discharge of industrial wastewater showed a downward trend at an average of 22.17 billion tons, accounting for $39 \%$ of the average total wastewater discharge of 56.978 billion tons. Although water pollution control policies have played a role in preventing further deterioration of water pollution, water pollution incidents have occurred frequently in recent years. According to the information management system of public health emergencies from 2004 to 2015, 126 water pollution incidents were reported in 23 provinces, along with 16,571 cases and three deaths. Among them, the main cause of pollution is industrial wastewater pollution and household waste pollution. As industrial water pollution has a great impact on the environment and the health of residents, comprehensive treatment of industrial wastewater has become one of the major problems to be targeted for an urgent solution.

It is worth noting that, although investment in wastewater treatment in China from the years 2000-2015 has improved, the proportion of such investment in industrial pollution sources declined from $41.78 \%$ in 2001 to $15.30 \%$ in 2015 . With limited investment in industrial wastewater treatment, the efficiency of such treatment must be improved to ameliorate the low water environment quality. Therefore, how to evaluate the efficiency of industrial wastewater treatment and put forward reasonable reform measures are key points.

In the face of severe water pollution situation, all provinces and cities in China have actively invested in water environment management funds driven by national energy conservation and emissions reduction policies. However, due to differences in the natural environment, economic and technological levels, industrial structure, and other aspects in China's 31 provinces and cities, their water environment management effects are also different across time and space. The industrial wastewater emissions of 31 provinces and nine (Beijing, Shanxi, Shanghai, Anhui, Jiangxi, Hainan, Chongqing, Guizhou, and Tibet) exhibited a growth trend, while the other 22 all showed a downward trend. For the industrial GDP of the 31 provinces and cities, four (Shanxi, Heilongjiang, Shanghai, and Gansu) showed a declining trend, with the other 27 ones showed a growth trend. With the visible decrease of industrial GDP, the discharge of industrial wastewater in Heilongjiang and Gansu decreased, while it increased in Shanxi and Shanghai. Under an increase of industrial GDP, the discharge of industrial wastewater in 20 provinces and cities showed a decreasing trend, With economic development and environmental regulation policies, the change in industrial GDP is not completely consistent with that of industrial wastewater discharge. How to improve desirable outputs and reduce undesirable outputs under limited investment in water pollution control are key issues in the study of industrial water pollution control efficiency.

Data envelopment analysis (DEA), first introduced by Charnes et al. (1978) [1], is a non-parametric method for measuring the relative efficiency of peer decision making units (DMUs) with multiple inputs and multiple outputs. DEA has been widely used for efficiency evaluation of schools, hospitals, banks, airports, etc. (Charnes et al. [2]; Ouellette and Vierstraete [3]; Hu et al. [4]; Satoshi and Masako [5]; Assaf [6]). Tone [7] proposed a slacks-based measure of efficiency, which is non-radial and non-oriented, and deals with input/output slacks directly. To analyze the dynamic intertemporal effect in production, Fare and Grosskopf [8] firstly proposed a dynamic DEA model, which can only measure the radial efficiency of input and output with proportional changes. Following that, the dynamic DEA and SBM were combined by Tone and Tsutsui [9], who set up a dynamic SBM model without requiring the input and output factors to change proportionally.

To sum up our research, we take 31 provinces, municipalities, and autonomous regions in China as the sample, use a dynamic SBM model that covers GDP growth as the carry-over factor to support 
the inter-temporal effect, and dynamically evaluate the efficiency of industrial wastewater treatment, including undesirable output in China between 2010 and 2015. We study the change in trend and the cause of water pollution prevention and control efficiency. The results are more reliable and can provide a scientific foundation for improving regional industrial wastewater treatment efficiency and water environmental treatment.

The rest of this study runs as follows. Section 2 is a literature review. Section 3 is the research method. Section 4 is the empirical results. Section 5 is the discussion. Section 6 is the conclusions.

\section{Literature Review}

Data envelopment analysis (DEA) has recently been widely used to evaluate environment performance. Besides the aspect of citizen's involving to environment issue, such as Budică et al. [10], the current literature on wastewater treatment efficiency mainly focuses on three aspects as follows.

(1) Studies on wastewater treatment efficiency with countries or regions as subjects. On one hand, scholars directly analyze wastewater treatment efficiency with input and output data. Zhao et al. [11], for example, analyzed investment efficiency in China's wastewater treatment based on the expansion-type DEA method, showing that efficiency is low in each region, the especially northern and northwest regions, which are the most serious. Chen [12] conducted static analysis on input and output data of 30 provinces in 2013 and dynamic analysis of panel data from 2004 to 2013 to evaluate the efficiency of industrial wastewater treatment from the three dimensions of 'Social-Economy-Ecology' in China by using the BCC model and Malmquist productivity index model. Shi [13] evaluated treatment efficiency of industrial water pollution of China in 2012 by using a three-stage DEA model, which presented that treatment efficiency of industrial water pollution in the eastern region is higher than that in the central and western regions. Hu et al. [14] used the Malmquist index to calculate the wastewater treatment efficiency of Hubei Province in China from 2003 to 2010, indicating the optimized allocation of inputs and outputs. Li and Zhao [15] adopted the DEA method and Malmquist index to separately evaluate the static efficiency and dynamic efficiency of industrial wastewater treatment in China. Chen and Fan [16] calculated the industrial wastewater treatment efficiency in China by DEA and the trend of treatment efficiency by the Malmquist index and concluded that national efficiency should be improved, and that technological improvement in eastern and northeastern China has an increasing impact on wastewater treatment efficiency, which should be strengthened in the central and west regions. Scholars also utilize wastewater discharge indicators as factors to evaluate the environmental efficiency of national or specific areas as their research subject (Liu et al. [17]; Yu, [18]; Chen and Pei [19]; Yang and $\mathrm{Lu}[20])$.

(2) Studies on wastewater treatment efficiency with enterprises and industries as subjects. Rahbari et al. [21] used the Malmquist productivity index and windows analysis to assess the efficiency of a Khuzestan steel company treatment plant and calculate the treatment plant efficiency in removing pollutants. Liu et al. [22] evaluated the wastewater treatment efficiency of 10 mineral industries from 2003 to 2012 based on DEA models with undesirable outputs and found that the average wastewater treatment efficiency of China's mineral industry is increasing and that the efficiency gap of mining industries and smelting industries tends to be stable during the time period. Fan et al. [23] calculated the efficiency of water pollution treatment in 38 industrial sectors by the DEA-Malmquist model by using the annual data of water pollution treatment from 2005 to 2013, showing that the water pollution treatment efficiencies of different sectors are different. Hu et al. [24] evaluated 20 enterprises in industrial parks in the Taihu basin by using DEA methods. Yang and Li [25] used the DEA-SBM model to measure the TFE (Total Factor Efficiency) of wastewater control in 39 industrial sectors of China from 2003 to 2014 and found that the TFE of wastewater control in the industrial sectors is quite low and far from satisfactory.

(3) Studies on wastewater treatment efficiency with wastewater treatment plants as research subjects. Lorenzo-Toja et al. [26] employed a DEA window analysis on a set of wastewater treatment plants for a four-year interval between 2009 and 2012 with the aim of understanding the annual 
behavior of WWTPs in terms of environmental sustainability. Giovanna et al. [27] applied AHP/NDDF (novel integrated analytic hierarchy process/non-radial directional distance functions) to investigate the environmental efficiency of 96 Tuscan (Italian) wastewater treatment plants (WWTPs). Gemar et al. [28] evaluated dynamic eco-efficiency of WWTPs using the dynamic weighted Russell directional distance model (WRDDM) and obtained an eco-productivity change index for each major component (costs, pollutants removal, and greenhouse gas emissions). Guerrini et al. [29] used a double bootstrap DEA method to measure the energy costs of wastewater treatment plants and identified how they can be reduced on 127 WWTPs in Tuscany, Italy for the year 2014. Molinos-Senante et al. [30] assessed and compared the productivity growth of WWTPs operating under four alternative technologies with a sample of 99 WWTPs by a meta-frontier Malmquist productivity index. Lorenzo-Toja et al. [31] analyzed the operational efficiency of a group of 113 WWTPs in Spain, combining the two approaches of LCA and DEA to obtain environmental benchmarks for inefficient plants. Ramón Fuentes et al. [32] examined the efficiency of 158 wastewater treatment plants in the region of Valencia (Spain) using an input-oriented order-m model of conditional efficiency. Lledó [33] evaluated the efficiency of a sample of wastewater treatment plants by applying the weighted slacks-based measure model, which allows for assigning weights to the inputs and outputs according to their importance. Hernandez-Sancho et al. [33] applied a non-radial DEA methodology to calculate energy efficiency indices for a sample of WWTPS located in Spain. Pachura and Ocipa-Kubicka [34] introduced pro-ecological activities implemented by the Water Supply and Sewerage Joint Stock of the Czestochowa District.

The above literature shows that research on the efficiency of wastewater treatment has the following characteristics. First, from the research subject, the literature comprehensively includes national, regional, industrial factors, and WWTPs in China. Second, from the research method, not only is the traditional DEA model used, but also a combination of traditional DEA models and improvement models. Third, from the time dimension, there are both static and intertemporal studies.

The literature noted above enriches the current research field and provides us with a good perspective and method. However, most studies are based on radial measures, consisting of CCR and the BCC models, that have the problem of not being able to appropriately measure the efficiency of weakly efficient DMUs (Charnes et al.) [35]. To solve this problem, Tone [7] proposes a slacks-based measure (SBM) approach to measure efficiency.

The traditional dynamic DEA model, such as the Malmquist index, and static models used for performance evaluation usually assume that the impacts from input and output variables are limited to the current period and do not take into account the cross-term effect of carry-over activities in production. Therefore, Fare and Grosskopf [8] initially set up a dynamic DEA model that can only measure the radial efficiency of input and output with proportional changes. Following that, dynamic DEA and SBM are combined in Tone and Tsutsui [9], who propose a dynamic SBM model without requiring the input and output factors to change proportionally. It is necessary to point out that, since the undesirable outputs are produced during the process of production with the expected output, the dynamic SBM is able to deal with this issue.

This paper therefore uses the input and output data of industrial wastewater treatment in 31 provinces of China. We then adopt the dynamic SBM model to calculate the impact of the carry-over activities across time periods, while considering undesirable output at the same time, to accurately analyze the efficiency of industrial wastewater treatment in China.

\section{Methods}

DEA is a manner for measuring the relative efficiency of a set of decision making units (DMUs) that apply multiple inputs to produce multiple outputs in a given time period. Various methods measure efficiency deviations over time; e.g. window analysis by Klopp [36] and the Malmquist index [37] by Färe and Grosskopf [8]. Even if these models can take into account the time change effect, they usually ignore carry-over activities between two consecutive terms and only focus on the separate time period(s), independently training local optimization in a single period. In the 
real business world, long-term planning and investment are subjects of great distress for business growth. The dynamic DEA model of Färe and Grosskopf [8] is the first innovative contribution for such purpose. They introduce the dynamic aspects of production into the conventional DEA model when multi-outputs are involved and formulate several inter-temporal models, which have become the origin for many later studies on dynamic DEA. Chen and Van dalen [38], Nemoto and Goto [39], Sueyoshhi and Sekitani [40], and Chang et al. [41] develop dynamic DEA, and Tone and Tsutsui [10] assimilate SBM into dynamic DEA.

The non-oriented model can process inputs and outputs individually. This means that the model is proper for non-uniformly distributed inputs and outputs, and different weights can be dispensed to the inputs and outputs depending on their degree of position. Tone and Tsutsui [9] divide carry-overs into four types for an analysis foundation of dynamic DEA models: (1) desirable (good), (2) undesirable (bad), (3) discretionary (free), and (4) non-discretionary (fixed). The DEA model variables can be separated into three categories: input, output, and non-oriented. SBM can be used to identify the optimum solution.

According to the characteristics of carry-overs, we classify real GDP into a desirable carry-over that resembles profit carried forward of GDP to the next term. The main focus of this study is that governments in all countries must consider reducing $\mathrm{CO}_{2}$ emissions when looking to create/sustain economic growth. Therefore, GDP performance in one period will have an influence on the efficiency in the next period. We use dynamic SBM models that can evaluate the overall efficiency of DMUs for the whole term period as well as the term period efficiencies. For these cases, a single-period optimization model does not fit for performance evaluation. To cope with a long-term point of view, the dynamic DEA model incorporates carry-over activities and helps to measure a period's specific efficiency based on long-term optimization during the whole period. It also calculates the system and period efficiencies under dynamic conditions. One important finding is that the method for calculating system efficiency in the literature produces over-estimated scores when discounting the dynamic nature. This makes it necessary to conduct dynamic analysis whenever data are available (Kao [42]).

Another main consideration for the study is to choose a dynamic model for calculation. This study utilizes the model established based on the expectations of Tone and Tsutsui [9], which include $\mathrm{T}$ periods and $\mathrm{n}$ DMUs, each of which has different inputs, outputs, and carry-overs in period $\mathrm{t}$ and period $\mathrm{t}$ links to the next period, $\mathrm{t}+1$.

Let $\mathrm{n}$ DMUs $(\mathrm{j}=1, \ldots, \mathrm{n})$ carry over $\mathrm{T}$ term periods $(\mathrm{t}=1, \ldots, \mathrm{T})$.

There are $\mathrm{m}$ inputs $(\mathrm{i}=1, \mathrm{k}, \mathrm{m})$ of the DMUs.

F: non-discretionary (fixed) inputs ( $\mathrm{i}=1, \mathrm{k}, \mathrm{p})$;

S: output $(i=1, k, s)$;

P: non-discretionary (fixed) outputs ( $\mathrm{i}=1, \mathrm{k}, \mathrm{r}$ );

z: link (carry-over) has four categories of good, bad, free, and fixed;

w: weight.

We present the following non-oriented model:

$$
\begin{gathered}
\rho_{0}^{*}=\min \frac{\frac{1}{\mathrm{~T}} \sum_{\mathrm{t}=1}^{\mathrm{T}} \mathrm{W}^{\mathrm{t}}\left[1-\frac{1}{\mathrm{~m}+\mathrm{nbad}}\left(\sum_{\mathrm{i}=1}^{\mathrm{m}} \frac{\mathrm{w}_{\mathrm{i}}^{-} \mathrm{s}_{\mathrm{it}}^{-}}{\mathrm{x}_{\mathrm{iot}}}+\sum_{\mathrm{r}=1}^{\mathrm{nbad}} \frac{\mathrm{s}_{\mathrm{it}}^{\mathrm{bad}}}{\mathrm{z}_{\mathrm{rot}}^{\text {bad }}}\right)\right]}{\frac{1}{\mathrm{~T}} \sum_{\mathrm{t}=1}^{\mathrm{T}} \mathrm{W}^{\mathrm{t}}\left[1+\frac{1}{\mathrm{~s}+\text { ngood }}\left(\sum_{\mathrm{l}=1}^{\mathrm{s}} \frac{\mathrm{w}_{\mathrm{i}}^{+} \mathrm{s}_{\mathrm{it}}^{+}}{\mathrm{y}_{\mathrm{iot}}}+\sum_{\mathrm{r}=1}^{\mathrm{ngood}} \frac{\mathrm{s}_{\mathrm{it}}^{\text {good }}}{\mathrm{z}_{\mathrm{rot}}^{\text {good }}}\right)\right]} \\
\sum_{\mathrm{r}=1}^{\mathrm{n}} \mathrm{z}_{\mathrm{rjt}}^{\alpha} \lambda_{j}^{\mathrm{t}}=\sum_{\mathrm{j}=1}^{\mathrm{n}} \mathrm{z}_{\mathrm{rjt}}^{\alpha} \lambda_{j}^{\mathrm{t}+1}(\forall \mathrm{i} ; \mathrm{t}=1, \ldots, \mathrm{T}-1)
\end{gathered}
$$


Equation (2) shows the connection equation between periods $t$ and $t+1$.

$$
\begin{aligned}
& x_{i o t}=\sum_{j=1}^{n} x_{i j t} \lambda_{j}^{t}+s_{i t}^{-}(i=1, \ldots, m ; t=1, \ldots, T) \\
& x_{i o t}^{f i x}=\sum_{j=1}^{n} x_{i o t}^{f i x} \lambda_{j}^{t}(i=1, \ldots, F ; t=1, \ldots, T) \\
& \mathrm{y}_{\mathrm{lot}}=\sum_{\mathrm{l}=1}^{\mathrm{n}} \mathrm{y}_{\mathrm{ljt}} \lambda_{\mathrm{j}}^{\mathrm{t}}-\mathrm{s}_{\mathrm{lt}}^{+}(\mathrm{l}=1, \ldots, \mathrm{s} ; \mathrm{t}=1, \ldots, \mathrm{T}) \\
& y_{\text {lot }}^{\text {fix }}=\sum_{l=1}^{n} y_{\text {lot }}^{\text {fix }} \lambda_{j}^{\mathrm{t}}(1=1, \ldots, r ; t=1, \ldots, T) \\
& z_{\text {iot }}^{\text {good }}=\sum_{j=1}^{n} z_{\text {iot }}^{\text {good }} \lambda_{j}^{t}-s_{i t}^{\text {good }}(i=1, \ldots, \text { ngood } ; t=1, \ldots, T) \\
& \mathrm{z}_{\mathrm{iot}}^{\mathrm{bad}}=\sum_{\mathrm{j}=1}^{\mathrm{n}} \mathrm{z}_{\mathrm{ijt}}^{\mathrm{bad}} \lambda_{\mathrm{j}}^{\mathrm{t}}+\mathrm{s}_{\mathrm{it}}^{\mathrm{bad}}(\mathrm{i}=1, \ldots, \mathrm{nbad} ; \mathrm{t}=1, \ldots, \mathrm{T}) \\
& z_{\text {iot }}^{\text {free }}=\sum_{j=1}^{n} z_{i j t}^{\text {free }} \lambda_{j}^{t}+s_{i t}^{\text {free }}(i=1, \ldots, \text { nfree } ; t=1, \ldots, T) \\
& z_{i o t}^{\mathrm{fix}}=\sum_{j=1}^{\mathrm{n}} \mathrm{z}_{\mathrm{ijt}}^{\mathrm{fix}} \lambda_{j}^{\mathrm{t}}(\mathrm{i}=1, \ldots, \mathrm{nfix} ; \mathrm{t}=1, \ldots, \mathrm{T}) \\
& \sum_{j=1}^{n} \lambda_{j}^{t}=1(t=1, \ldots, T) \\
& \lambda_{j}^{t} \geq 0, s_{i t}^{-} \geq 0, s_{i t}^{+} \geq 0, s_{i t}^{\text {good }} \geq 0, s_{i t}^{\text {bad }} \geq 0 \text { and } s_{i t}^{\text {free }}: \text { free }(\forall i, t)
\end{aligned}
$$

Here, we show the solution that is most efficient:

$$
\rho_{0 \mathrm{t}}=\frac{1-\frac{1}{\mathrm{~m}+\mathrm{nbad}}\left(\sum_{\mathrm{i}=1}^{\mathrm{m}} \frac{\mathrm{w}_{\mathrm{i}}^{-} \mathrm{s}_{\mathrm{iot}}^{-*}}{\mathrm{x}_{\mathrm{iot}}}+\sum_{\mathrm{r}=1}^{\mathrm{nbad}} \frac{\frac{s}{\mathrm{rot}}_{\mathrm{rod}}^{\mathrm{bad} *}}{z_{\mathrm{rot}}^{\mathrm{bod}}}\right)}{1+\frac{1}{\mathrm{~s}+\text { ngood }}\left(\sum_{\mathrm{l}=1}^{\mathrm{s}} \frac{\mathrm{w}_{\mathrm{i}}^{+} \mathrm{s}_{\mathrm{it}}^{+*}}{\mathrm{y}_{\mathrm{lot}}}+\sum_{\mathrm{r}=1}^{\mathrm{ngood}} \frac{\mathrm{s}_{\mathrm{rot}}^{\text {goot }}}{z_{\mathrm{rot}}^{\text {good }}}\right)}(\mathrm{i}=1, \ldots, \mathrm{T}) .
$$

\section{Empirical Result}

\subsection{Data and Variables}

The research sample covers the 30 regions of China and their wastewater resources according to the China Energy Statistical Yearbook dataset and the National Bureau of Statistics of the People's Republic of China for the period 2011-2015. We use five variables. As shown in Table 1, the regions are: Shanghai, Shandong, Shanxi, Guangdong, Guangxi, Yunnan, Inner Mongolia, Tianjin, Beijing, Sichuan, Ningxia, Gansu, Jilin, Anhui, Jiangxi, Jiangsu, Liaoning, Hebei, Henan, Qinghai, Guizhou, Chongqing, Shaanxi, Zhejiang, Hainan, Hubei, Hunan, Heilongjiang, Xinjiang, and Fujian. The five variables are two output variables, two input variables, and one carry-over variable. The output variables are industrial wastewater treatment and industrial output, the two input variables are industrial water consumption and facility operation cost, and the carry-over variable is industrial waste. This study 
concludes with implications for theory research, as these variables may lead to a better understanding and merging with the input variables, output variables, and carry-over variable of recent studies.

Table 1. Regions and input, output, and carry-over variables.

\begin{tabular}{|c|c|c|c|}
\hline Regions & Input Variables & Output Variables & $\begin{array}{c}\text { Carry-Over } \\
\text { Variables }\end{array}$ \\
\hline $\begin{array}{l}\text { 1.Shanghai, 2. Shandong, 3. Shanxi, } \\
\text { 4. Guangdong, 5. Guangxi, 6. Yunnan, } \\
\text { 7. Inner Mongolia, 8. Tianjin, 9. Beijing, } \\
\text { 10. Sichuan, 11. Ningxia, 12. Gansu, 13. Jilin, } \\
\text { 14. Anhui, 15. Jiangxi, 16. Jiangsu, 17. Liaoning, } \\
\text { 18. Hebei, 19. Henan, 20. Qinghai, 21. Guizhou, } \\
\text { 22. Chongqing, 23. Shaanxi, 24. Zhejiang, } \\
\text { 25. Hainan, 26. Hubei, 27. Hunan, } \\
\text { 28. Heilongjiang, 29. Xinjiang, 30. Fujian }\end{array}$ & $\begin{array}{l}\text { 1. Industrial water } \\
\text { consumption } \\
\text { 2. Facility operation } \\
\text { cost }\end{array}$ & $\begin{array}{l}\text { 1. Industrial } \\
\text { wastewater treatment } \\
\text { 2. Industrial output }\end{array}$ & Industrial waste \\
\hline
\end{tabular}

In order to clarify the influence of regions, we conducted an analysis on all 30 regions. Table 2 presents the descriptive statistics of the input, output, and carry-over variables' results as follows. (1) Industrial water consumption: the average of all regions is 250,234 ten thousand $\mathrm{m}^{3}$. Jiangsu has the most industrial water consumption in 2015 at 1,406,721 ten thousand $\mathrm{m}^{3}$, while Chongqing has the lowest industrial water consumption at 130 ten thousand $\mathrm{m}^{3}$ in 2011. (2) Facility operation cost: the average is 224,095 ten thousands during 2011 to 2015 . Hebei has the greatest facility operation cost at 933,519 ten thousand in 2011, while Hunan has the lowest at 6474 ten thousand in 2015. (3) Industrial wastewater treatment: in general, the higher the treatment, the better the result. In order to clarify the relative influences of these variables, this study adopted the DSBM model to evaluate each region's industrial wastewater treatment. The 30 regions' average is 175,008 ten thousand tons; Hubei has the maximum treatment of 933,519 ten thousand tons in 2011, while Hunan has the lowest treatment region of 6533 ten thousand tons in 2013. (4) Industrial output: the average increased from 2011 to 2015 at an annual average rise of 20,902 billion; Guangdong has the highest industrial output at 72,812 billion in 2015, while Qinghai has the lowest of 1670 billion in 2011. (5) Industrial waste: the average of the 30 regions is 72,290 ten thousand tons from 2011-2015. Jiangsu has the most at 246,298 ten thousand tons in 2011, while Hainan has the least at 6744 ten thousand tons in 201.

Table 2. Descriptive Statistics.

\begin{tabular}{|c|c|c|c|c|c|}
\hline & Variables & St Dev & Ave & Max & Min \\
\hline \multirow{2}{*}{ Input } & (I) Industrial water consumption (ten thousand $\mathrm{m}^{3}$ ) & 327,462 & 250,234 & $1,354,854$ & 130 \\
\hline & (I) Facility operation cost (ten thousands) & 197,400 & 224,095 & 966,723 & 9309 \\
\hline \multirow{2}{*}{ Output } & $\begin{array}{l}\text { (O) Industrial wastewater treatment (ten thousand } \\
\text { tons) }\end{array}$ & 166,312 & 175,008 & 933,519 & 6533 \\
\hline & (O) Industrial output (billion) & 15,610 & 20,902 & 72,812 & 1670 \\
\hline Carry-over & (CB) Industrial waste (ten thousand tons) & 58,142 & 72,290 & 246,298 & 6744 \\
\hline
\end{tabular}

\subsection{Empirical Results and Comparison of Efficiency Score for Each Region}

We used DEA-Solver software to evaluate the efficiency of the 30 regions of China and analyze each region's different efficiency ranking, by using the DSBM DEA model of Kaoru Tone and Miki Tsutsuib [9]. In order to identify the relationship between industrial wastewater treatment and industrial output, we took each one based on its own specifications to see how to improve it towards the efficient frontier. Table 3 shows the differences between the rank and higher/lower efficiency scores of each region. From the results, there are eight regions with efficiency scores equal to 1 by the DSBM DEA model (Guangdong, Beijing, Sichuan, Qinghai, Hainan, Hunan, Fujian, and Jiangsu), and their industrial outputs are not all higher than other regions. In contrary, Shaanxi, Gansu, Shanxi, Heilongjiang, Tianjin, and Ningxia have efficiency scores lower than 0.5. The efficiency scores 
are lower, because some regions no longer are able to support industrial wastewater treatment or industrial output.

Table 3. Overall efficiency score results of each region.

\begin{tabular}{cccccc}
\hline Region & Overall Score & Rank & Region & Overall Score & Rank \\
\hline Guangdong & 1 & 1 & Hebei & 0.81 & 16 \\
Beijing & 1 & 1 & Jilin & 0.76 & 17 \\
Sichuan & 1 & 1 & Hubei & 0.76 & 18 \\
Qinghai & 1 & 1 & Zhejiang & 0.70 & 19 \\
Hainan & 1 & 1 & Inner Mongolia & 0.61 & 20 \\
Hunan & 1 & 1 & Shanghai & 0.56 & 21 \\
Fujian & 1 & 1 & Anhui & 0.56 & 22 \\
Jiangsu & 1 & 1 & Liaoning & 0.55 & 23 \\
Henan & 0.95 & 9 & Xinjiang & 0.50 & 24 \\
Jiangxi & 0.94 & 10 & Shaanxi & 0.47 & 25 \\
Shandong & 0.93 & 11 & Gansu & 0.46 & 26 \\
Yunnan & 0.91 & 12 & Shanxi & 0.45 & 27 \\
Guizhou & 0.85 & 13 & Heilongjiang & 0.34 & 28 \\
Chongqing & 0.85 & 14 & Tianjin & 0.31 & 29 \\
Guangxi & 0.83 & 15 & Ningxia & 0.26 & 30 \\
\hline
\end{tabular}

\subsection{The Improvement or Regression of Each Region's Efficiency Score}

Table 4 shows the 30 regions and their yearly change in efficient score from 2011 to 2015. The results suggest that over the whole period, 10 regions return to a previous, including Shanxi, Guangxi, Inner Mongolia, Anhui, Liaoning, Hebei, Guizhou, Hubei, Heilongjiang, and Xinjiang. Those regions in general seem to not be high in industrial output. A period when a temporary efficiency score declines, during which industrial output and industrial wastewater treatment activities drop, is generally identified by a fall in the efficiency score over successive years.

We now list those regions with a decline in efficiency score during this period, sorted by the number of times the scores fell (once, twice, three times, or four times). (i) Once: seven regions see a one-time drop in efficiency score (Shanghai, Guangxi, Yunnan, Jilin, Jiangxi, Liaoning, and Hebei). (ii) Twice: six regions have efficiency scores drop twice in this period (Shanxi, Tianjin, Ningxia, Gansu, Hubei, and Heilongjiang). (iii) Three times: three regions have efficiency scores drop three times in this period (Anhui, Zhejiang, and Xinjiang). (iv) Four times: only Inner Mongolia's efficiency score drops four times in this period, giving it an efficiency ranking of 20. Over the whole period 2011-2015, some regions show continued improvement, such as Shanghai improving to 0.7 in its efficiency score. In the same period, Ningxia improves to 0.8 in its efficiency score and Gansu improves 0.61 in its efficiency score. Three regions exhibit improvement in efficiency scores above 0.5 in this study. 
Table 4. Improvement or regression of each region's efficiency score for 2011-2015.

\begin{tabular}{|c|c|c|c|c|c|c|c|}
\hline Region & Overall Score & Rank & 2012-2011 & 2013-2012 & 2014-2013 & 2015-2014 & 2015-2011 \\
\hline Shanghai & 0.56 & 21 & 0.32 & -0.01 & 0.06 & 0.34 & 0.70 \\
\hline Shandong & 0.93 & 11 & 0.33 & 0.00 & 0.00 & 0.00 & 0.33 \\
\hline Shanxi & 0.45 & 27 & 0.05 & -0.17 & 0.02 & -0.13 & -0.23 \\
\hline Guangdong & 1.00 & 1 & 0.00 & 0.00 & 0.00 & 0.00 & 0.00 \\
\hline Guangxi & 0.83 & 15 & 0.00 & 0.00 & 0.00 & -0.62 & -0.62 \\
\hline Yunnan & 0.91 & 12 & 0.00 & 0.00 & -0.35 & 0.34 & 0.00 \\
\hline Inner Mongolia & 0.61 & 20 & -0.24 & -0.15 & -0.16 & -0.11 & -0.65 \\
\hline Tianjin & 0.31 & 29 & 0.11 & -0.13 & 0.09 & -0.02 & 0.05 \\
\hline Beijing & 1.00 & 1 & 0.00 & 0.00 & 0.00 & 0.00 & 0.00 \\
\hline Sichuan & 1.00 & 1 & 0.00 & 0.00 & 0.00 & 0.00 & 0.00 \\
\hline Ningxia & 0.26 & 30 & 0.04 & -0.02 & -0.02 & 0.81 & 0.80 \\
\hline Gansu & 0.46 & 26 & 0.11 & -0.11 & -0.09 & 0.70 & 0.61 \\
\hline Jilin & 0.76 & 17 & -0.03 & 0.08 & 0.33 & 0.00 & 0.37 \\
\hline Anhui & 0.56 & 22 & -0.03 & -0.04 & 0.07 & -0.16 & -0.16 \\
\hline Jiangxi & 0.94 & 10 & -0.24 & 0.24 & 0.00 & 0.00 & 0.00 \\
\hline Jiangsu & 1.00 & 8 & 0.00 & 0.00 & 0.00 & 0.00 & 0.00 \\
\hline Liaoning & 0.55 & 23 & 0.03 & 0.01 & 0.05 & -0.32 & -0.23 \\
\hline Hebei & 0.81 & 16 & 0.00 & 0.00 & 0.00 & -0.75 & -0.75 \\
\hline Henan & 0.95 & 9 & 0.26 & 0.00 & 0.00 & 0.00 & 0.26 \\
\hline Qinghai & 1.00 & 1 & 0.00 & 0.00 & 0.00 & 0.00 & 0.00 \\
\hline Guizhou & 0.85 & 13 & 0.00 & 0.00 & 0.00 & -0.61 & -0.61 \\
\hline Chongqing & 0.85 & 14 & 0.00 & 0.00 & -0.48 & 0.48 & 0.00 \\
\hline Shaanxi & 0.47 & 25 & 0.09 & -0.05 & 0.04 & 0.03 & 0.11 \\
\hline Zhejiang & 0.70 & 19 & -0.09 & -0.03 & -0.02 & 0.40 & 0.26 \\
\hline Hainan & 1.00 & 1 & 0.00 & 0.00 & 0.00 & 0.00 & 0.00 \\
\hline Hubei & 0.76 & 18 & 0.35 & 0.00 & -0.34 & -0.11 & -0.10 \\
\hline Hunan & 1.00 & 1 & 0.00 & 0.00 & 0.00 & 0.00 & 0.00 \\
\hline Heilongjiang & 0.34 & 28 & -0.12 & 0.00 & 0.04 & -0.17 & -0.25 \\
\hline Xinjiang & 0.50 & 24 & -0.20 & -0.02 & 0.06 & -0.22 & -0.38 \\
\hline Fujian & 1.00 & 1 & 0.00 & 0.00 & 0.00 & 0.00 & 0.00 \\
\hline
\end{tabular}

\section{Discussion}

Most studies use traditional DEA and SBM, which employ cross-section datasets to measure the efficiency scores of DMUs. We believe it is more interesting to observe a region's changing trend in its score or rank during the data's collection period. Hence, we used the DSBM model to calculate the efficiency scores or ranks, while at the same time we computed the average efficiency scores and average ranks. Clearly, environmental topics in recent years have become more popular in the world, as many scholars discuss the lack of wastewater treatment efficiency and the negative effects from sewage sludge water contents. Some regions in China have put forth a lot of resources into increasing industrial wastewater treatment, yet some have lower efficiency scores than other regions. In other words, some regions' efficiency scores have fallen in order to control industrial water consumption investment, facility operation costs, or industrial waste.

From 2011 to 2015 in China, from the absolute value of the decline in industrial wastewater discharge, Fujian, Jiangsu, and Guangxi regions were reduced by 86.45 million tons, 39.871 million tons, and 379.81 million tons industrial wastewater treatment. In addition, from the increase in industrial wastewater discharge, Guizhou, Jiangxi, and Shanghai rank among the top three in the country at 8854 million tons, 5216 million tons, and 23.13 million tons, respectively. Those regions are not the top/bottom regions in terms of efficiency score in this study. Clearly, the lower efficiency score regions are able to achieve a high efficiency score, and each region has the ability to target the best efficiency score, no matter when trying to increase industrial output or reducing industrial wastewater treatment. This likely reflects that a region should reduce its industrial water consumption input. Our findings enhance the results from earlier studies. Below, we report the 30 regions of China and their efficiency scores and the analysis conclusions.

From the efficiency rank changes of the 30 regions during 2011 to 2015, it does not appear that higher industrial output regions have improved more than other regions, such as for Shandong, 
Guangdong, Jiangsu, Qinghai, and Zhejiang. The efficiency scores from the 30 regions exhibit some volatility, with 13 regions' efficiency score volatility clustering close to 0, like Beijing, Chongqing, Shandong, Guangdong, and Sichuan. By contrast, Anhui, Inner Mongolia, Zhejiang, and Xinjiang see efficiency scores drop more than other regions during this period, and thus they should adjust their input/output variables to increase their efficiency scores in the following year.

\section{Conclusions}

Improving desirable outputs and reducing undesirable outputs under the limited investment in water pollution control are key issues when investigating the efficiency of industrial water pollution control. This study used the Dynamic SBM model to assess wastewater resources for research samples covering the 30 regions of China. The model included two output variables with industrial wastewater treatment and industrial output, two input variables with industrial water consumption and facility operation cost, and one carry-over variable with industrial waste. The empirical results show that from the efficiency rank changes of the 30 regions for 2011-2015, regions with higher industrial output do not appear to have improved versus other regions. The 30 regions' efficiency scores show some volatility, with 13 regions' efficiency score volatility clustering close to 0 . In contrast, for Anhui, Inner Mongolia, Zhejiang, and Xinjiang, their efficiency scores fell more than other regions in this period and thus should adjust their input/output variables to increase their efficiency scores.

This study further showed that many lower-/middle-/high industrial output regions do not achieve a balance between industrial output and industrial wastewater treatment. How to find a balance between the two for any region is a vitally important issue for industrial wastewater treatment policy makers. Under such a circumstance, a region's industrial output may not actually be highly efficient.

Author Contributions: Conceptualization: R.Z. and Y.-H.C.; methodology: C.-C.L. and Y.-H.C.; software: C.-C.L., J.-H.L. and Y.-H.C.; validation: Y.F. and Y.-H.C.; formal analysis: J.-H.L. and C.-C.L.; investigation: R.Z., Y.-H.C. and Y.F.; resources: Y.-H.C. and Y.F.; data curation: J.-H.L., Y.F. and C.-C.L.; writing-original draft preparation: C.-C.L., J.-H.L. and Y.F.; writing-review and editing: R.Z. and Y.-H.C.; visualization: C.-C.L. and J.-H.L.; supervision: Y.-H.C., R.Z. and Y.F.; project administration: Y.-H.C. and R.Z.; funding acquisition: R.Z. and Y.F.

Funding: This research was funded by "Young Academic Innovation Team of Northwest University of Political Science and Law", Evaluation of Government Environmental Performance Auditing (016166523), the Improvement of Legal System of PPP model of Urban Sewage Treatment Industry in China (17BFX042), Study on Cost Structure, Appropriate Scale and Service Efficiency of Urban Sewage Treatment(17YJA790062), Study on Efficiency Evaluation and Promotion Path of Urban Water Pollution Control in Shaanxi Province (2015D064).

Conflicts of Interest: The authors declare no conflict of interest.

\section{References}

1. Charnes, A.; Cooper, W.W.; Rhodes, E. Measuring the efficiency of decision making units. Eur. J. Oper. Res. 1978, 2, 429-444. [CrossRef]

2. Charnes, A.; Cooper, W.W.; Lewin, A.Y.; Seiford, L.M. Data Envelopment Analysis: Theory, Methodology, and Applications; Springer Science \& Business Media: Berlin, Germany, 1995.

3. Ouellette, P.; Vierstraete, V. An evaluation of the efficiency of Québec's school boards using the Data Envelopment Analysis method? Appl. Econ. 2005, 37, 1643-1653. [CrossRef]

4. Hu, H.H.; Qi, Q.; Yang, C.-H. Evaluation of China's regional hospital efficiency: DEA approach with undesirable output. J. Oper. Res. Soc. 2012, 63, 715-725. [CrossRef]

5. Ohsato, S.; Takahashi, M. Management Efficiency in Japanese Regional Banks: A Network DEA. Procedia Soc. Behav. Sci. 2015, 172, 511-518. [CrossRef]

6. Assaf, A. Accounting for size in efficiency comparisons of airports. J. Air Transp. Manag. 2009, 15, $256-258$. [CrossRef]

7. Tone, K. A slacks-based measure of efficiency in data envelopment analysis. Eur. J. Oper. Res. 2001, 130, 498-509. [CrossRef]

8. Fare, R.; Grosskopf, S. Intertemporal Production Frontiers: With Dynamic DEA; Kluwer: Norwell, MA, USA, 1996.

9. Tone, K.; Tsutsui, M. Dynamic DEA: A slacks-based measure approach. Omega 2010, 38, 145-156. [CrossRef] 
10. Budică, I.; Busu, O.V.; Dumitru, A.; Purcaru, M.-L. Waste management as commitment and duty of citizens. Pol. J. Manag. Stud. 2015, 11,7-16.

11. Zhao, S.; Wang, H.; Qiu, L. Investment Efficiency Analysis of Chinese Industrial Wastewater Treatment Based on Expansion-Type DEA. In Proceedings of the International Workshop on Computer Science for Environmental Engineering and EcoInformatics CSEEE 2011: Computer Science for Environmental Engineering and EcoInformatics, Kunming, China, 29-31 July 2011; pp. 342-347.

12. Chen, S. Evaluation of Industrial Wastewater Treatment Efficiency from "Social- Economy- Ecology" Three Dimensions and Analysis of Regional Differences. J. Yibin Univ. 2016, 1612, 119-124.

13. Shi, F. A Study on Regional Treatment Efficiency of Industrial Water Pollution in China-Based on Three-stage DEA Method. East. China Econ. Manag. 2014, 2808, 40-45.

14. Hu, X.; Wu, H.; Ge, D. Method for efficiency assessment of wastewater treatment and application based on DEA. Water Resour. Prot. 2013, 29, 77-81.

15. Li, L.; Zhao, P. Study on Efficiency of Industrial Wastewater Treatment in China. Res. Dev. Mark. 2011, 27, 1093-1095.

16. Chen, X.; Fan, D. Empirical Study on Status of Industrial Water Pollution and Treatment Efficiency in China. Stat. Inf. Forum 2009, 24, 30-35.

17. Liu, B.; Wang, B.; Xue, G. On assessment of public spending efficiency of environment protection in local China: Base on three-stage bootstrapped DEA. J. Zhongnan Univ. Econ. Law 2016, 1, 89-95.

18. Yu, W. Public Appeal, Government Intervention and Environmental Governance Efficiency-An Empirical Analysis Based on Provincial Panel Data. J. Yunnan Univ. Financ. Econ. 2015, 31, 132-139.

19. Chen, M.; Pei, X. A Study of the Efficiency of China's Financial Policy for Environmental Governance: Based on DEA Cross Evaluation. Contemp. Financ. Econ. 2013, 4, 27-36.

20. Yang, J.; Lu, Y. Environmental Investment Efficiency in China based on three-stage DEA model. J. Syst. Eng. 2012, 27, 699-711.

21. Rahbari, K.; Hassani, A.H.; Mehrgan, M.R. Evaluating the process efficiency of industrial wastewater treatment plants using data envelopment analysis approach case study: Khuzestan steel company treatment plant. Bulg. Chem. Commun. 2018, 50, 124-132.

22. Liu, Y.; Gong, B.; Liu, X. An appraise of wastewater treatment efficiency in China mineral industries based on DEA models with undesirable outputs. Chin. J. Environ. Eng. 2017, 11, 2073-2078.

23. Fan, C.; Gu, H.; Jiang, H. The Treatment Efficiency of Industrial Water Pollution and Its Sectoral Differences in China. Ecol. Econ. 2016, 32, 174-178.

24. Hu, W.; Qian, M.; Liu, G. Study on wastewater treatment efficiency for enterprises in Taihu basin based on DEA model. Chin. J. Environ. Eng. 2014, 8, 1417-1422.

25. Yang, W.; Li, L. Efficiency Evaluation and Policy Analysis of Industrial Wastewater Control in China. Energies 2017, 10, 1201. [CrossRef]

26. Yago, L.-T.; Ian, V.-R.; Desirée, M.-N. Dynamic environmental efficiency assessment for wastewater treatment plants. Int. J. Life Cycle Assess. Febr. 2018, 23, 357-367.

27. D'Inverno, G.; Carosi, L.; Romano, G. Water pollution in wastewater treatment plants: An efficiency analysis with undesirable output. Eur. J. Oper. Res. 2018, 269, 24-34. [CrossRef]

28. Gemar, G.; Gomez, T.; Molinos-Senante, M. Assessing changes in eco-productivity of wastewater treatment plants: The role of costs, pollutant removal efficiency, and greenhouse gas emissions. Environ. Impact Assess. Rev. 2018, 69, 24-31. [CrossRef]

29. Guerrini, A.; Romano, G.; Indipendenza, A. Energy Efficiency Drivers in Wastewater Treatment Plants: A Double Bootstrap DEA Analysis. Sustainability 2017, 9, 1126. [CrossRef]

30. Molinos-Senante, M.; Hernandez-Sancho, F.; Sala-Garrido, R. Comparing the dynamic performance of wastewater treatment systems: A metafrontier Malmquist productivity index approach. J. Environ. Manag. 2015, 161, 309-316. [CrossRef]

31. Lorenzo-Toja, Y.; Vazquez-Rowe, I.; Chenel, S. Eco-efficiency analysis of Spanish WWTPs using the LCA plus DEA method. Water Res. 2015, 68, 651-666. [CrossRef] 
32. Ramón, F.; Francesc, H.-S.; Teresa, T. Productivity of Wastewater Treatment Plants in the Valencia Autonomous Region, Spain. In Proceedings of the International Conference on Regional Science: Innovation and Geographical Spillovers: New Approaches and Evidence, Tarragona, Spain, 18-20 November 2015; Volume 11, pp. 1-16. Available online: https://old.aecr.org/images/ImatgesNoticies/2015/4/A4_Reus_Todos.pdf (accessed on 29 May 2019).

33. Hernández-Sancho, F.; Molinos-Senante, M.; Sala-Garrido, R. Energy efficiency in Spanish wastewater treatment plants: A non-radial DEA approach. Sci. Total Environ. 2011, 409, 2693-2699. [CrossRef]

34. Pachura, P.; Ociepa-Kubicka, A. Eco-management and audit scheme (EMAS) functioning on the example of the water supply and sewerage joint stock company of the Częstochowa district. Pol. J. Manag. Stud. 2014, 10, 143-150.

35. Charnes, A.; Cooper, W.W.; Thrall, R.M. Classifying and characterizing efficiencies and inefficiencies in data envelopment analysis. Oper. Res. Lett. 1986, 5, 105-110. [CrossRef]

36. Klopp, G.A. The Analysis of the Efficiency of Production System with Multiple Inputs and Outputs. Ph.D. Dissertation, Industrial and System Engineering College, University of Illinois at Chicago, Chicago, IL, USA, 1985.

37. Malmquist, S. Index numbers and indifference surfaces. Trab. Estad. 1953, 4, 209-242. [CrossRef]

38. Chen, C.M.; van Dalen, J. Measuring dynamic efficiency: Theories and anintegrated methodology. Eur. J. Oper. Res. 2010, 203, 749-760. [CrossRef]

39. Nemoto, J.; Goto, M. Dynamic data envelopment analysis modeling inter-temporal behavior of a firm in the presence of productive inefficiencies. Econ. Lett. 1999, 64, 51-56. [CrossRef]

40. Sueyoshhi, T.; Sekitani, K. Return to scale in dynamic DEA. Eur. J. Oper. Res. 2005, 161, 536-544. [CrossRef]

41. Chang, H.; Choy, H.L.; Cooper, W.W.; Ruefli, T.W. Using Malmquist indexes to measure changes in the productivity and efficiency of US accounting firms before and after the Sarbanes-Oxley Act. Omega 2009, 37, 951-960. [CrossRef]

42. Kao, C. Dynamic data envelopment analysis: A relational analysis. Eur. J. Oper. Res. 2013, 227, $325-330$. [CrossRef]

(C) 2019 by the authors. Licensee MDPI, Basel, Switzerland. This article is an open access article distributed under the terms and conditions of the Creative Commons Attribution (CC BY) license (http://creativecommons.org/licenses/by/4.0/). 